\title{
Postscript: COVID-19 and SDG progress
}

\author{
Stephanie A. Macht ${ }^{1}$ (D), Ross L. Chapman ${ }^{1}$ (D) and Janna Anneke Fitzgerald ${ }^{2}$ \\ ${ }^{1}$ School of Business and Law, Central Queensland University - Sydney Campus, Sydney, Australia and ${ }^{2}$ Griffith Business \\ School, Griffith University, Southport, Queensland, Australia \\ Author for correspondence: Stephanie Macht, E-mail: s.macht@cqu.edu.au
}

In writing this Special Issue editorial, we were acutely aware that the world has changed dramatically from the time of the development of the articles contained therein. While the findings and conclusions of the seven articles remain just as relevant to a post-COVID world (or to the current mid-COVID environment!), we felt it would be a valuable addition to the Special Issue, to provide an update on current (late-2020) progress toward achieving the Sustainable Development Goals (SDGs), and the particular role of management education and research in this goal.

According to the Social Progress Imperative blog (2020), even before COVID-19 hit the world in early 2020, it was clear that all of the SDGs would not be achievable by 2030. The Social Progress Imperative is a US-based non-profit focused on redefining how the world measures success. Established in 2012, it developed the Social Progress Index (SPI) to measure how well countries and communities convert their resources into social and environmental outcomes that impact the lives of people every day - like health, safety, education, rights and opportunity to understand precisely how people are really living and who is being left behind.

The SPI (Social Progress Imperative, 2020) is a measure of the quality of life, independent of economic factors and captures outcomes related to all 17 SDGs. The SPI chooses to focus on the effect of policy on social outcomes to try and work backward to see why countries are failing at certain indicators. The index was first released in 2014 and is a comprehensive collection of components measuring social and environmental performance. The SPI compiles 57 components asking the question about basic human needs, foundations of well-being and opportunity to have a quality of life, such as wealth, social inclusion and access to higher education. This quality of life measure is about well-being and prioritises perceived social progress to improve the lives of people around the world, rather than measuring gross domestic product.

The main criticism of the SPI is that the measure is somewhat ill-defined, although others believe a large number of indicators is a strength rather than a weakness (World Economic Forum, 2014). In addition, the index chooses to omit economic indicators of any kind. As Ensor (2016) states in his report on the gathering of social innovators in Reykjavik, Iceland in May 2016: 'Ignoring economic inequality blinds you to the lack of opportunity that the poor have in many respects and ignores clear correlations between income inequality and, say, 'access to advanced education' (a measurement of the SPI).' Nevertheless, Ensor concludes that the SPI is part of the growing reality, in which businesses and social enterprises will play a greater role in development, beyond being wealth creators (Ensor, 2016).

The SPI shows that while some SDGs have made good world-wide progress (such as Nutrition and Basic Medical Care and progress made in developing countries like Gambia, Ethiopia and Tunisia), other goals have been stagnant or even reversed. In 2020, the index measured 'social progress' going backwards and it was predicted that the world will not achieve the goals until 2082. The decline is mainly attributable to the 'Personal Rights and Inclusiveness' component, which has been in decline since 2011. In addition, the world has stagnated on Environmental 
Quality and Personal Safety. Further, the COVID-19 pandemic is thought to have delayed achievement of these goals by another 10 years to 2092 (Ipsos, 2020a).

This research, which was undertaken by the Social Progress Imperative and Ipsos (a large market research company) indicates that, during the COVID-19 pandemic, the majority of people want social progress (such as life expectancy, education, inclusiveness, etc.), rather than economic growth. It also found that young people (under 35 years old) prefer their country prioritises social outcomes after COVID-19 when recovering. When looking at the priorities by country it is revealed that during the pandemic, globally, respondents would prioritise health and well-being (72\%) over economic growth (28\%). When asked what their countries should prioritise more after the pandemic is over, the research still showed a primary focus on improved social outcomes (53\%) globally. However, there is much more discrepancy over what countries should focus on in the future versus what countries focus on in the present. Here the finding showed that a majority of Australians believe economic growth should be the priority in the longer term (60\%). Similarly, in South Africa (58\%), Mexico (57\%), Italy (54\%), USA (52\%) and UK (51\%), as opposed to countries like Brazil, India, Chile and Russia who chose for social progress as the priority $(64 \%, 59 \%, 71 \%$ and $69 \%$, respectively) (Ipsos, 2020b).

It is clear that working towards the SDGs is essential for social and planetary well-being, especially in this time of crisis. Universities can do their job, including management scholars. In April 2020, the Sustainable Development Solutions Network (SDSN) held an online forum discussing the effects of COVID-19 on the advancement of the SDGs. Overwhelmingly, the participants at this forum concluded that the COVID-19 pandemic had significant impacts (mostly negative, but a few positive, for example, the environment) on the SGDs and that the SDGs have 'profound relevance to the response and recovery of the crisis' (SDSN Australia/Pacific, 2020).

Acknowledging that universities have been greatly impacted by the COVID-19 pandemic, the SDSN forum concluded that the SDGs should continue to matter within the education (teaching), research and operation of today's universities. Similarly, we believe business schools should promote the need for an SDG-led recovery, using terms such as 'leaving no-one behind' in the roadmap to sustainability. This outcome of the April 2020 SDSN forum is particularly relevant to the management scholars who will be responsible for evidence-based policy-making and who are also building management science and expertise. Providing policy-relevant advice on the SDGs is an opportunity for management scholars to continue showcasing this role.

Business and industry will also play a key role through innovation, access to resources and as a source of employment. Exploiting the mantra 'Never waste a crisis,' Fara Azat and Ranjit Voola speak of three interrelated aspects as the underlying driving forces for business to engage in the SDG agenda (Azat \& Voola, 2020). Firstly, in rethinking the role of business in global sustainability, COVID-19 has highlighted the need for changing the business mindset towards sustainability and viewing the SDGs as a strategic opportunity for businesses to grow. Universities play a critical role in rethinking the role of businesses by developing students as future business leaders and executives, but also in mapping their own efforts relating to the SDGs. Many universities have already joined the UN Principles for Responsible Management Education as a holistic approach to management education, but this does not necessarily result in SDG-relevant management research.

The second driving force is technological readiness. COVID-19 has highlighted the importance of technological connectivity to keep businesses functional. This includes the use of telehealth and remote learning, two technological drivers that have been rapidly fast-tracked over the last 6-9 months with significantly more speed than possible in a pre-COVID world. The third driver to engage with the SDGs is social innovation. As mentioned earlier, businesses use innovative practices to keep thriving, doing more with less and, hopefully reducing their environmental impacts and improving social responsibilities. 


\section{Where to from here?}

UN Secretary-General António Guterres stated: 'We need to turn the recovery into a real opportunity to do things right for the future' (UN Sustainable Development Goals, 2020). According to the UN, the pandemic is 'an unprecedented wake-up call, laying bare deep inequalities and exposing precisely the failures that are addressed in the 2030 Agenda for Sustainable Development and the Paris Agreement on climate change' (UN Sustainable Development Goals, 2020).

Leveraging this moment of crisis, when usual policies and social norms have been disrupted, bold steps can guide the world back on track towards the SDGs. This is an opportunity for a profound systemic shift to a more sustainable economy that works for both people and the planet.

From the above discussion, it is clear that the world needs to consider 'success' as more than measures of gross domestic product and unemployment rates. As Michael Green (CEO of the Social Progress Imperative) states: 'COVID-19 is not just about health and economies, this crisis has to be managed in a way that no one is left behind. We must focus on social progress.' As stated, in Australia the majority believe that, in the short term, social progress should be heading the political agenda, but in the longer-term economic growth should take precedence, but not necessarily at the expense of social progress.

The pandemic crisis was perpetuated by the underlying issues such as inequality, exclusion and disparity, which were already in decline before the COVID-19 crisis hit (Christ \& Burritt, 2019; Ipsos, 2020b). We must create informed responses to address the underlying social issues. We cannot manage these issues if we do not measure them.

In addition, an alternate form of leadership, one we have not seen for many years, has arisen due to COVID-19: leadership for the greater good. This occurs when leaders create value for society through transparency, accountability and ethical decision-making. For example, driving a sense of togetherness by our senior politicians led to a positive increase in public perception of our National and State leaders as well as a rethink on how States, Territories and Federal entities can work better together (Wilson, Pallant, Bednall, \& Gray, 2020).

As stated, this crisis has consolidated the importance of leaders acquiring the knowledge, skills and mindsets to solve complex societal and management decision-making problems. Society looks at universities to provide education that supports these skills and mindsets, and to encourage, stimulate and support responsible, impactful management research programs, working with industry to build the evidence and minimise the theory-practice gap.

\section{References}

Azat, F., \& Voola, R. (2020). Sustainable development goals more urgent than ever in a post COVID world. Sydney Business Insights. Retrieved from https://sbi.sydney.edu.au/sustainable-development-goals-more-urgent-than-ever-in-a-post-covidworld/ (accessed 26 September 2020).

Christ, K. L., \& Burritt, R. L. (2019). Implementation of sustainable development goals: The role for business academics. Australian Journal of Management, 44(4), 571-593.

Ensor, C. (2016). A new index to measure social progress, but what is it really telling us? Retrieved from http://www.humanosphere. org/social-business/2016/05/a-new-index-to-measure-social-progress-but-what-is-it-really-telling-us/ (accessed 26 September 2020).

Ipsos. (2020a). Majority favours social progress over economic growth in the wake of corona virus pandemic. Retrieved from https://www.ipsos.com/en-us/news-polls/Majority-Favors-Social-Progress-over-Economic-Growth-in-the-Wake-of-theCoronavirus-Pandemic/ (accessed 26 September 2020).

Ipsos. (2020b). Covid-19 Recovery preferences and priorities. Retrieved from https:/www.ipsos.com/sites/default/files/ct/ news/documents/2020-09/ipsos_spi_deck__ffinal_.9.10.20.pdf/ (accessed 26 September 2020).

SDSN Australia/Pacific. (2020). Covid-19: What does it mean for SDGs and universities - forum summary. Retrieved from http://ap-unsdsn.org/wp-content/uploads/SDSN-ACTS-Forum-5-COVID-19_Summary_Final.pdf/ (accessed 26 September 2020).

Social Progress Imperative. (2020). Index to action to impact. Retrieved from https://www.socialprogress.org/ (accessed 26 September 2020). 
Social Progress Imperative blog. (2020). The 2020 Social Progress Index Sparks Discussion. Retrieved from https://socialprogress. blog/2020/09/10/announcing-the-2020-social-progress-index/ Accessed September 26, 2020 (accessed 27 September 2020).

UN Sustainable Development Goals. (2020). The sustainable development goals: our framework for COVID - 19 recovery. Retrieved from https://www.un.org/sustainabledevelopment/sdgs-framework-for-covid-19-recovery/ (accessed 16 September 2020).

Wilson, S., Pallant, J., Bednall, T., \& Gray, S. (2020). Public perceptions of leadership for the greater good during the first wave of the COVID-19 pandemic. Melbourne: Swinburne University of Technology. https://doi.org/10.25916/5ed98fd01a684

World Economic Forum. (2014). Is the Social Progress Index the real deal? Retrieved from https://www.weforum.org/agenda/ 2014/12/is-the-social-progress-index-the-real-deal/ (accessed 26 September 2020).

Cite this article: Macht SA, Chapman RL, Fitzgerald JA (2020). Postscript: COVID-19 and SDG progress. Journal of Management \& Organization 26, 1073-1076. https://doi.org/10.1017/jmo.2020.42 